Annals of Pure and Applied Mathematics

Vol. 18, No. 1, 2018, 91-94

ISSN: 2279-087X (P), 2279-0888(online)

Published on 30 August 2018

www.researchmathsci.org

DOI: http://dx.doi.org/10.22457/apam.v18n1a13

Annals of

Pure and Applied Mathematics

\title{
On the Non-Linear Diophantine Equation $61^{\mathrm{x}}+67^{\mathrm{y}}=\mathrm{z}^{2}$ and $67^{\mathrm{x}}+73^{\mathrm{y}}=\mathrm{z}^{2}$
}

\author{
Satish Kumar', Sani Gupta ${ }^{2}$ and Hari Kishan ${ }^{3}$ \\ Department of Mathematics, D. N. College Meerut, U.P., India. \\ E-mail: skg22967@gmail.com, ${ }^{2}$ sanigoel@gmail.com; ${ }^{3}$ harikishan10@ @rediffmail.com \\ ${ }^{2}$ Corresponding author
}

Received 30 June 2018; accepted 29 August 2018

Abstract. In this paper, we consider the non-linear Diophantine equations $61^{x}+67^{y}=z^{2}$ and $67^{x}+73^{y}=z^{2}$, where $x, y$ and $z$ are non-negative integers. It has been shown that these non-linear Diophantine equations have no solution.

Keywords: Diophantine Equations, Catalan's Conjecture, Exponential Equations.

\section{AMS Mathematics Subject Classification(2010): 11D61}

\section{Introduction}

If a Diophantine equation has as an additional variable or variables occurring as exponents, it is an exponential Diophantine equation like as the equation of the Fermat- Catalan conjecture and Beal's conjecture, $a^{m}+b^{n}=c^{k}$ with inequality restrictions on the exponents. A general theory for such equations is not available; particular cases such as Catalan's conjecture have been tackled. In 1884, Catalan [5] conjectured that the four tuple $(a, b, x, y)=(3,2,2,3)$ is the unique solution of the Diophantine equation $a^{x}-b^{y}=1$, where $a, b, x$ and $y$ are non-negative integers with $\min \{a, b, x, y\}>1$. In 2004, Mihailescu [6] proved the Catalan's conjecture and Corollary that $(p, x, y)=(2,3$, 3 ) is the unique solution of the Diophantine equation $1+p^{x}=z^{2}$, where $p$ is prime and $\min \{p, x, y\}>$,1 . In 2011, A. Suvarnamani [7] showed that the Diophantine equations $4^{x}$ $+7^{y}=z^{2}$ and $4^{x}+11^{y}=z^{2}$ have no solution, where $x, y$ and $z$ are non-negative integers. In 2012, Sroysang [8] proved that the Diophantine equation $8^{x}+19^{y}=z^{2}$ has the unique solution $(x, y, z)=(1,0,3)$, where $x, y$ and $z$ are non-negative integers. In 2013, Sroysang [9] proved that the Diophantine equation $7^{x}+8^{y}=z^{2}$, where $x, y$ and $z$ are non-negative integers, has the unique solution $(x, y, z)=(0,1,3)$. In 2014, Sroysang [10] proved that the Diophantine equation $4^{\mathrm{x}}+10^{\mathrm{y}}=\mathrm{z}^{2}$ has no solution, where $x, y$ and $z$ are non-negative integers. In 2014, Sroysang [11] proved that the Diophantine equations $7^{\mathrm{x}}+19^{\mathrm{y}}=\mathrm{z}^{2}$ and $7^{\mathrm{x}}+91^{\mathrm{y}}=\mathrm{z}^{2}$, have no solution, where $x, y$ and $z$ are non-negative integers. In 2017, Acu [1] showed that the Diophantine equation $2^{x}+5^{y}=z^{2}$, where $x, y$ and $z$ are non-negative integers, has only two solutions $(x, y, z)=(3,0,3)$ and $(2,1,3)$. In 2018, Burshtein [3] written a note on the Diophantine equation $2^{a}+7^{b}=c^{2}$, where $a$ and $b$ are odd integers. In 2018, Burshtein [2] discussed on an open problem of Chotchaisthit, on the Diophantine 


\section{Satish Kumar, Sani Gupta and Hari Kishan}

equation $2^{\mathrm{x}}+\mathrm{p}^{\mathrm{y}}=\mathrm{z}^{2}$, where $\mathrm{p}$ are particular prime and $\mathrm{y}=1$. In 2018, Burshtein [4] also discussed on the Diophantine equation $2^{\mathrm{x}}+\mathrm{p}^{\mathrm{y}}=\mathrm{z}^{2}$, where $\mathrm{p}$ are prime.

In this paper we consider some particular exponential Diophantine equations

and

$$
\begin{aligned}
& 61^{\mathrm{x}}+67^{\mathrm{y}}=\mathrm{z}^{2} \\
& 67^{\mathrm{x}}+73^{\mathrm{y}}=\mathrm{z}^{2}
\end{aligned}
$$

where $x, y$, and $z$ are non-negative integers. We will use the Catalan's conjecture and congruency theory to solve these non-linear Diophantine equations.

\section{Preliminaries}

Proposition 2.1. (a, b, $x, y)=(3,2,2,3)$ is the unique solution of the Diophantine equation $\mathrm{a}^{\mathrm{x}}-\mathrm{b}^{\mathrm{y}}=1$, where $\mathrm{a}, \mathrm{b}, \mathrm{x}$ and $\mathrm{y}$ are integers with $\min \{\mathrm{a}, \mathrm{b}, x, y)>1$.

Proof: See in [6].

Lemma 2.1. The Diophantine equation $1+67^{\mathrm{y}}=\mathrm{z}^{2}$ has no solution, where $\mathrm{y}$ and $\mathrm{z}$ are non-negative integers.

Proof: Let $\mathrm{y}$ and $\mathrm{z}$ are non-negative integers. Then we consider three cases.

Case I. If $y=0$. Then $z^{2}=2$, which is not possible.

Case II. If $y=1$. Then $z^{2}=68$, also not possible.

Case III. If $y>1$. Then $z^{2}=1+67^{y}>68$.

This implies $z>8$. Here $\min \{y, z\}>1$, by Proposition, no solution.

Lemma 2.2. The Diophantine equation $1+73^{y}=z^{2}$ has no solution, where $y$ and $z$ are non-negative integers.

Proof: Let $\mathrm{y}$ and $\mathrm{z}$ are non-negative integers. Then we consider three cases.

Case I. If $y=0$. Then $z^{2}=2$, which is not possible.

Case II. If $\mathrm{y}=1$. Then $\mathrm{z}^{2}=74$, also not possible.

Case III. If $y>1$. Then $z^{2}=1+73^{y}>74$.

This implies $z>8$. Here $\min \{y, z\}>1$, by Proposition, no solution.

Lemma 2.3. The Diophantine equation $61^{\mathrm{x}}+1=\mathrm{z}^{2}$ has no solution, where $\mathrm{x}$ and $\mathrm{z}$ are non-negative integers.

Proof: Let $x$ and $z$ are non-negative integers. Then we consider three cases.

Case I. If $\mathrm{x}=0$. Then $\mathrm{z}^{2}=2$, which is not possible.

Case II. If $x=1$. Then $z^{2}=62$, also not possible.

Case III. If $x>1$. Then $z^{2}=61^{x}+1>62$.

This implies $z>7$. Here $\min \{x, z\}>1$, by Proposition, no solution.

Lemma 2.4. The Diophantine equation $67^{\mathrm{x}}+1=\mathrm{z}^{2}$ has no solution, where $\mathrm{x}$ and $\mathrm{z}$ are non-negative integers.

Proof: Let $\mathrm{x}$ and $\mathrm{z}$ are non-negative integers. Then we consider three cases.

Case I. If $\mathrm{x}=0$. Then $\mathrm{z}^{2}=2$, which is not possible.

Case II. If $x=1$. Then $z^{2}=68$, also not possible.

Case III. If $x>1$. Then $z^{2}=67^{x}+1>68$.

This implies $z>8$. Here $\min \{x, z\}>1$, by Proposition, no solution.

\section{Main theorem}

Theorem 3.1. The non-linear Diophantine equation $61^{\mathrm{x}}+67^{\mathrm{y}}=\mathrm{z}^{2}$ has no solution, where $x, y$, and $\mathrm{z}$ are non-negative integers. 
Proof: Let $x, y$, and $z$ are non-negative integers. Then there are three cases.

Case I. If $x=0$, then by Lemma 2.1, there is no non-negative integer solution.

Case II. If $x \geq 1$ and $y=0$, then by Lemma 2.3, also has no non-negative integer solution.

Case II. If $x \geq 1$ and $y \geq 1$, then $61^{x}$ and $67^{y}$ both are odd. Thus $z^{2}$ is even, then $\mathrm{z}^{2} \equiv 0(\bmod 3)$ or $\mathrm{z}^{2} \equiv 1(\bmod 3)$. Since $61 \equiv 1(\bmod 3)$ and $67 \equiv 1(\bmod 3)$ then $61^{\mathrm{x}} \equiv 1(\bmod 3)$ and $67^{\mathrm{y}} \equiv 1(\bmod 3)$. Therefore $\mathrm{z}^{2}=61^{\mathrm{x}}+67^{\mathrm{y}} \equiv 2(\bmod 3)$, which is a contradiction.

Corollary 3.1.1. The non-linear Diophantine equation $61^{\mathrm{x}}+67^{\mathrm{y}}=\mathrm{k}^{2 \mathrm{t}}$ has no solution, where $x, y$, and $z$ are non-negative integers, $k$ and $t$ are positive integer.

Proof: Suppose the non-linear Diophantine equation $61^{\mathrm{x}}+67^{\mathrm{y}}=\mathrm{k}^{2 \mathrm{t}}$, where $x, y$, and $z$ are non-negative integers, $k$ and $t$ are positive integer. Let $\mathrm{k}^{\mathrm{t}}=\mathrm{z}$, then Diophantine equation becomes $61^{\mathrm{x}}+67^{\mathrm{y}}=\mathrm{z}^{2}$, which has no solution by Theorem 3.1.

Corollary 3.1.2. The non-linear Diophantine equation $61^{\mathrm{x}}+67^{\mathrm{y}}=\mathrm{k}^{2 \mathrm{t}+4}$ has no solution, where $x, y$, and $z$ are non-negative integers, $k$ and $t$ are positive integer.

Proof: Let $\mathrm{k}^{\mathrm{t}+2}=\mathrm{z}$, then Diophantine equation becomes $61^{\mathrm{x}}+67^{\mathrm{y}}=\mathrm{z}^{2}$, which has no solution by Theorem 3.1 .

Theorem 3.2. The non-linear Diophantine equation $67^{\mathrm{x}}+73^{\mathrm{y}}=\mathrm{z}^{2}$ has no solution, where $x, y$, and $\mathrm{z}$ are non-negative integers.

Proof: Let $x, y$, and $\mathrm{z}$ are non-negative integers. Then there are three cases.

Case I. If $\mathrm{x}=0$, then by Lemma 2.2, there is no non-negative integer solution.

Case II. If $x \geq 1$ and $y=0$, then by Lemma 2.4 , also has no non-negative integer solution.

Case II. If $x \geq 1$ and $y \geq 1$, then $67^{x}$ and $73^{y}$ both are odd. Thus $z^{2}$ is even, then $\mathrm{z}^{2} \equiv 0(\bmod 3)$ or $\mathrm{z}^{2} \equiv 1(\bmod 3)$. Since $67 \equiv 1(\bmod 3)$ and $73 \equiv 1(\bmod 3)$ then $67^{\mathrm{x}} \equiv 1(\bmod 3)$ and $73^{\mathrm{y}} \equiv 1(\bmod 3)$. Therefore $\mathrm{z}^{2}=67^{\mathrm{x}}+73^{\mathrm{y}} \equiv 2(\bmod 3)$, which is a contradiction.

Corollary 3.2.1. The non-linear Diophantine equation $67^{\mathrm{x}}+73^{\mathrm{y}}=\mathrm{k}^{2 \mathrm{t}}$ has no solution, where $x, y$, and $\mathrm{z}$ are non-negative integers, $\mathrm{k}$ and $\mathrm{t}$ are positive integer.

Proof: Suppose the non-linear Diophantine equation $67^{\mathrm{x}}+73^{\mathrm{y}}=\mathrm{k}^{2 \mathrm{t}}$, where $x, y$, and $\mathrm{z}$ are non-negative integers, $\mathrm{k}$ and $\mathrm{t}$ are positive integer. Let $\mathrm{k}^{\mathrm{t}}=\mathrm{z}$, then Diophantine equation becomes $61^{\mathrm{x}}+67^{\mathrm{y}}=\mathrm{z}^{2}$, which has no solution by Theorem 3.2.

Corollary 3.2.2. The non-linear Diophantine equation $67^{\mathrm{x}}+73^{\mathrm{y}}=\mathrm{k}^{2 \mathrm{t}+4}$ has no solution, where $x, y$, and $\mathrm{z}$ are non-negative integers, $\mathrm{k}$ and $\mathrm{t}$ are positive integer.

Proof: Let $\mathrm{k}^{\mathrm{t}+2}=\mathrm{z}$, then Diophantine equation becomes $67^{\mathrm{x}}+73^{\mathrm{y}}=\mathrm{z}^{2}$, which has no solution by Theorem 3.2.

\section{Conclusion}

In this paper, we discussed the non linear Diophantine equations $61^{\mathrm{x}}+67^{\mathrm{y}}=\mathrm{z}^{2}$ and $67^{x}+73^{y}=z^{2}$ and find that these Diophantine equations have no solution for any non negative integers $x, y$ and $\mathrm{z}$.

\section{REFERENCES}

1. D. Acu, On the Diophantine equation $2^{\mathrm{x}}+5^{\mathrm{y}}=\mathrm{z}^{2}$, Gen. Math., 15(4) (2017) 145-148. 


\section{Satish Kumar, Sani Gupta and Hari Kishan}

2. N.Burshtein, Discussed an open problem of S. Chotchaisthit, on the Diophantine equation $2^{\mathrm{x}}+\mathrm{p}^{\mathrm{y}}=\mathrm{z}^{2}$, Annals of Pure and Applied Mathematics, 16 (1)(2018) 31-35.

3. N.Burshtein, A note on the Diophantine equation $2^{\mathrm{a}}+7^{\mathrm{b}}=\mathrm{c}^{2}$, Annals of Pure and Applied Mathematics, 16 (2) (2018) 305-306.

4. N.Burshtein, On the Diophantine equation $2^{\mathrm{x}}+\mathrm{p}^{\mathrm{y}}=\mathrm{z}^{2}$, Annals of Pure and Applied Mathematics, 16 (2) (2018) 471-477.

5. E.Catalan, A note on extraite dune lettre adressee a lediteur, J.Reine Angew. Math., 27 (1884) 192.

6. P.Mihailescu, On primary Cycalotomic units and a proof of Catalan's conjecture, $J$. Reine Angew. Math., 27 (2004) 167-195.

7. A.Suvarnamani, On the Diophantine equation $4^{x}+7^{y}=z^{2}$ and $4^{x}+11^{y}=z^{2}$, Sci. \& Tech. RMUTT J., 1 (1) (2011) 25-28.

8. B.Sroysang, On the Diophantine equation $8^{\mathrm{x}}+19^{\mathrm{y}}=\mathrm{z}^{2}$, Int. J. Pure \& Appl. Math., 81 (4) (2012) 601-604.

9. B.Sroysang, On the Diophantine equation $7^{\mathrm{x}}+8^{\mathrm{y}}=\mathrm{z}^{2}$, Int. J. Pure \& Appl. Math., 84 (2013) 111-114.

10. B.Sroysang, On the Diophantine equations $4^{\mathrm{x}}+10^{\mathrm{y}}=\mathrm{z}^{2}$, Int. J. Pure \& Appl. Math., 91 (1) (2014) 135-138.

11. B.Sroysang, On the Diophantine equation $7^{\mathrm{x}}+19^{\mathrm{y}}=\mathrm{z}^{2}$ and $7^{\mathrm{x}}+91^{\mathrm{y}}=\mathrm{z}^{2}$, Int. J. Pure \& Appl. Math., 92(1) (2014) 113-116. 